\title{
ERRATA
}

\section{New aspects for fusion energy using inertial confinement}

\section{H. HORA}

(This article appeared in Volume 25, Number 1, 2007, Pages 37-45)

We regret that due to a mix-up in the expressions "gain" and "efficiency," the third paragraph of Section 3 needs a correction and should be read as:

As far as ITER is concerned, the following facts need to be taken into consideration. This most favored project is scheduled to start working in 2016, where the energy gain is still rather modest: 500 MW electricity input should produce 500 MW fusion power during $500 \mathrm{~s}$, such that after conversion by $30 \%$ efficiency in an electric generator, an efficiency of 30\% may result as reported to the UN-Energy Conference, September 2004, in Sydney, Australia (Tran, 2004). The best measurement of MCF was with JET (Keilhacker, 1999), where a magnetically confined plasma torus for $2 \mathrm{~s}$ produced $16 \mathrm{MW}$ fusion power, by irradiation of $21 \mathrm{MW}$ neutral beam power, and $3 \mathrm{MW}$ heating by electromagnetic radiation. To this fusion efficiency of $66 \%$, one had to ignore the $100 \mathrm{MW}$ electricity that was needed to run the torus. If one takes the operation of JET into account, the efficiency of fusion energy is $12.9 \%$, and with $30 \%$ conversion to electricity, the total efficiency is $4.1 \%$ (to be compared with the $30 \%$ of ITER). It has to be understood that this experiment, by producing 16 MW fusion from $21 \mathrm{MW}$ neutral beams, and $3 \mathrm{MW}$ irradiations is a beam fusion experiment (Hora 2004) in some contradiction, in that beam fusion should be excluded. Nevertheless, it is the best result yet with magnetic confined plasmas.

\section{REFERENCES}

Hora, H. (2004). Developments in inertial fusion energy and beam fusion at magnetic confinement. Laser Part. Beams 22, $439-449$.

Hora, H. (2007). New aspects for fusion energy using inertial confinement. Laser Part. Beams 25, 37-45.

KeILHACKer, M. (1999). High fusion per performance from deuterium-tritium plasmas in JET. Nuclear Fusion 39, $209-221$.

\section{Proton stopping in plasmas considering $\mathrm{e}_{-}-\mathrm{e}_{-}$collisions}

\author{
M.D. BARRIGA-CARRASCO AND A.Y. POTEKHIN
}

(This article appeared in Volume 24, Number 4, 2006, Pages 553-558)

Below are corrections that must be made to the above paper:

The last line of the Abstract currently read:

... $50 \%$.

and it should read:

... $5 \%$.

The last line of Section 3 currently read:

... $50 \%$. 
and it should read:

... $5 \%$.

After Eq. (1) currently read:

... where $g(x)$ corresponds to

$$
g(x)=\int_{0}^{\infty} \frac{y d y}{\exp \left(D y^{2}-\beta \mu\right)+1} \ln \left|\frac{1+x}{1-x}\right|,
$$

and it should read:

...where $g(x)$ corresponds to

$$
g(x)=\int_{0}^{\infty} \frac{y d y}{\exp \left(D y^{2}-\beta \mu\right)+1} \ln \left|\frac{x+y}{x-y}\right|,
$$

Figure 3 is reprinted here with its original caption:
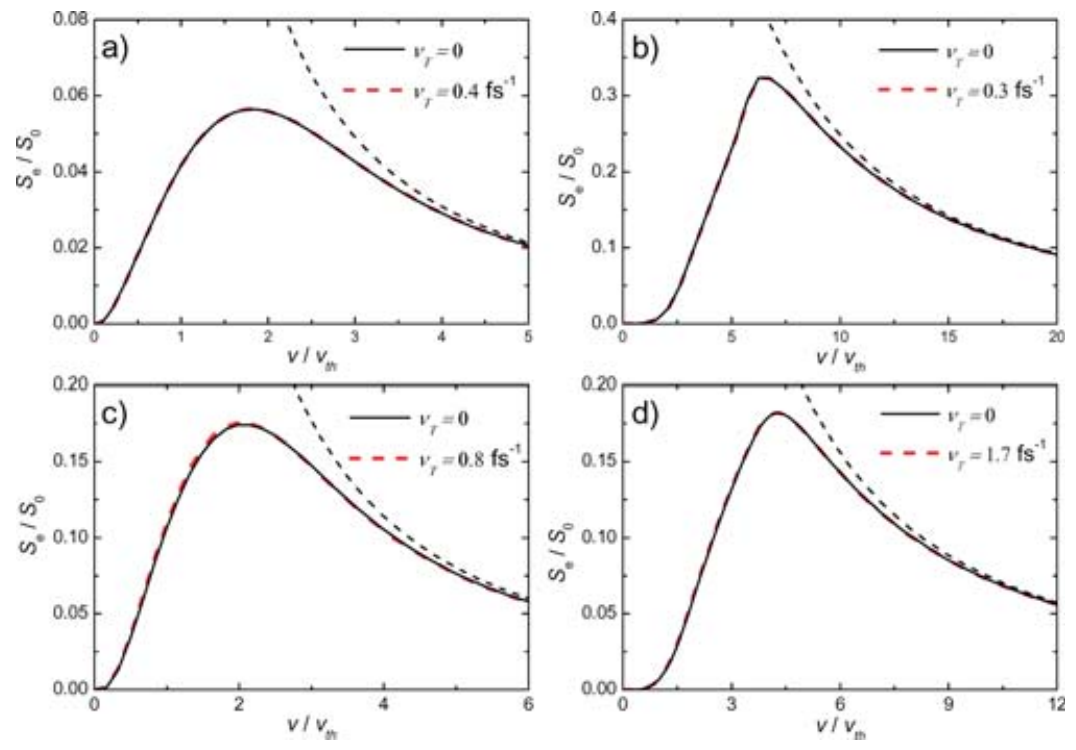

Fig. 3. Proton electronic stopping as a function of its velocity in different plasma targets considering and not considering $\mathrm{e}_{-}-\mathrm{e}_{-}$collisions. (a) $T_{\mathrm{e}}=100 \mathrm{eV}$ and $n_{\mathrm{e}}=10^{23} \mathrm{~cm}^{-3}$, (b) $T_{\mathrm{e}}=1 \mathrm{eV}$ and $n_{\mathrm{e}}=10^{23} \mathrm{~cm}^{-3}$, (c) $T_{\mathrm{e}}=10 \mathrm{eV}$ and $n_{\mathrm{e}}=10^{22} \mathrm{~cm}^{-3}$, and (d) $T=10 \mathrm{eV}$ and $n_{\mathrm{e}}=10^{24} \mathrm{~cm}^{-3}$. 